\title{
Promoção da saúde e participação comunitária em grupos locais organizados
}

\author{
Health promotion and community participation in organized local groups
}

Promoción de la salud y participación comunitaria en grupos locales organizados

\author{
Leticia Silveira Cardoso', Marta Regina Cezar-Vaz', Valdecir Zavarese da Costa", \\ Clarice Alves Bonow', Marlise Capa Verde de Almeida' \\ ' Universidade Federal do Rio Grande, Departamento de Enfermagem, \\ Programa de Pós-Graduação em Enfermagem. Rio Grande-RS, Brasil. \\ "Universidade Federal do Pampa, Curso de Graduação em Enfermagem. Uruguaiana-RS, Brasil.
}

\author{
Submissão: 09-11-2012 Aprovação: 18-11-2013
}

\section{RESUMO}

Objetivou-se conhecer a articulação dos grupos locais organizados com os profissionais da equipe da Estratégia Saúde da Família para a promoção da saúde socioambiental. Utilizou-se a técnica de entrevista semiestruturada gravada com 70 participantes dos 13 grupos investigados, analisadas segundo abordagem qualitativa de conteúdo. A categoria envolvimento comunitário revelou a mobilização profissional e comunitária pela gestão participativa em saúde. O interesse em participar dos grupos locais organizados indica as proposições individuais que se potencializam em coletivo e refletem-se no atendimento das necessidades humanas básicas psicobiológicas e socioambientais.

Descritores: Promoção da Saúde; Participação Comunitária; Programa Saúde da Família; Enfermagem em Saúde Comunitária.

\begin{abstract}
The study aimed at knowing the articulation of groups locally organized with the team of professionals of Family Health Strategy for promoting socio-environmental health. It was used the recorded semi-structured interview technique with 70 participants of 13 groups investigated, analyzed according to qualitative approach of content. The category consumer participation revealed the professional and collective mobilization for participative management in health. The interest in participating in groups locally organized indicates the individual propositions which increase collectively and can be noticed in the service of psychological basic human and socio-environmental necessities.
\end{abstract}

Key words: Health Promoting; Consumer Participation; Family Health Program; Community Health Nursing.

\section{RESUMEN}

Se objetivó conocer la articulación de los grupos organizados locales con los profesionales del equipo de la Estrategia Salud de la Familia para la promoción de la salud socio ambiental. Se utilizó la técnica de entrevista semi estructurada grabada con 70 participantes de los 13 grupos investigados, analizadas según el abordaje cualitativo de contenido. La categoría envolvimiento comunitario reveló la movilización profesional y comunitaria por la gestión participativa en salud. El interés en participar de los grupos locales organizados indica las proporciones individuales que se potencializan en colectivo se perciben en el atendimiento de las necesidades humanas básicas sicológicas y socio ambientales.

Palabras clave: Promoción de la Salud; Participación Comunitaria; Programa de Salud Familiar; Enfermería en Salud Comunitaria.

AUTOR CORRESPONDENTE Leticia Silveira Cardoso E-mail: Isc_enf@yahoo.com.br 


\section{INTRODUÇÃO}

A pluralidade como característica interpretativa do conceito de promoção da saúde exige esclarecer a priori que a abordagem em apresentação se pauta nas ações formuladas e aplicadas das políticas públicas em saúde, com destaque à gestão participativa em nível de atenção básica. Atenção que se traduz nas e pelas ações da equipe da Estratégia Saúde da Família, conduzidas para tornar a comunidade parte decisiva e fundamental no enfrentamento das limitações do próprio serviço de saúde e das vulnerabilidades socioambientais locais ${ }^{(1)}$.

As ações de trabalho referidas caracterizam-se pela tentativa em superar o paradigma biocentrado consolidado desde a década de $70^{(2)}$, cujo planejamento está direcionado para intervir nos aspectos do ambiente natural, ou seja, nas características da infraestrutura local das comunidades ${ }^{(3)}$. Para viabilizar tal pretensão o envolvimento dos moradores da comunidade constitui-se na essência propulsora para a realização de um trabalho com possibilidades de elevar a saúde da comunidade, sem eximir a realização das ações clínicas ${ }^{(3)}$.

O envolvimento comunitário no trabalho da equipe da Estratégia Saúde da Família responde parcialmente a pretensão de atuar, prioritariamente, na perspectiva do entendimento de saúde como condição determinada e condicionada por fatores socioambientais e não somente pela ausência de equilíbrio metabólico do organismo humano ${ }^{(4-5)}$.

Para a participação ativa da comunidade nas ações da referida equipe tornou-se condição a capacitação dos moradores das comunidades, de modo, a controlar a saúde individual e coletivamente. Controle que perpassa pela possibilidade de identificar os anseios, as necessidades humanas básicas, bem como, de intervir no ambiente natural local ${ }^{(6)}$.

Assim, o presente estudo responde: Como a participação comunitária nos grupos locais organizados promove a saúde socioambiental? Nesta perspectiva, a particularidade do que se propõe é fortalecer os potenciais das comunidades, ou seja, dos seus moradores para controlar, amenizar e evitar o aparecimento de enfermidades ou agravos. Para tanto, objetivou-se conhecer a articulação dos grupos locais organizados com os profissionais da equipe da Estratégia Saúde da Família para a promoção da saúde socioambiental.

\section{METODOLOGIA}

Estudo exploratório-descritivo e analítico, realizado em 13 grupos comunitários localizados em 03 municípios adstritos à Terceira Coordenadoria Regional de Saúde do Estado do Rio Grande do Sul - Brasil. Os participantes foram selecionados a partir dos seguintes critérios de elegibilidade: estar adstrito ao território de cobertura da Estratégia Saúde da Família (ESF) no período do levantamento das informações a respeito do cenário de investigação - 2008; desenvolver suas atividades no mínimo há seis meses e não se configurar como um grupo de atendimento a patologias preconizadas ministerialmente para intervenção da ESF.

A população do estudo compôs-se por 70 envolvidos exclusivamente em um dos grupos comunitários investigados, quais sejam: 05 grupos de artesãs, 04 grupos de moradores, 02 grupos de conselheiros locais de saúde, 01 grupo de pescadores e 01 grupo de recicladores de resíduos sólidos. Houve ainda a perda dos participantes de 01 grupo de educação, de 01 de pescadores e outro de conselheiros devido à interrupção ou a inatividade no período da coleta de dados. Esta se realizou por meio de entrevista semiestruturada gravada em 2009 e 2010.

Aplicou-se análise qualitativa de conteúdo ${ }^{(7)}$ construindo-se duas categorias empíricas - $\mathbf{O}$ envolvimento comunitário nos grupos locais organizados e $\mathbf{O}$ interesse da comunidade em participar dos grupos locais organizados a partir da utilização do software NVivo versão 7.0, apresentadas na Figura 1.

Figura 1 - Participação comunitária: envolvimento e interesse em participar dos grupos locais organizados.

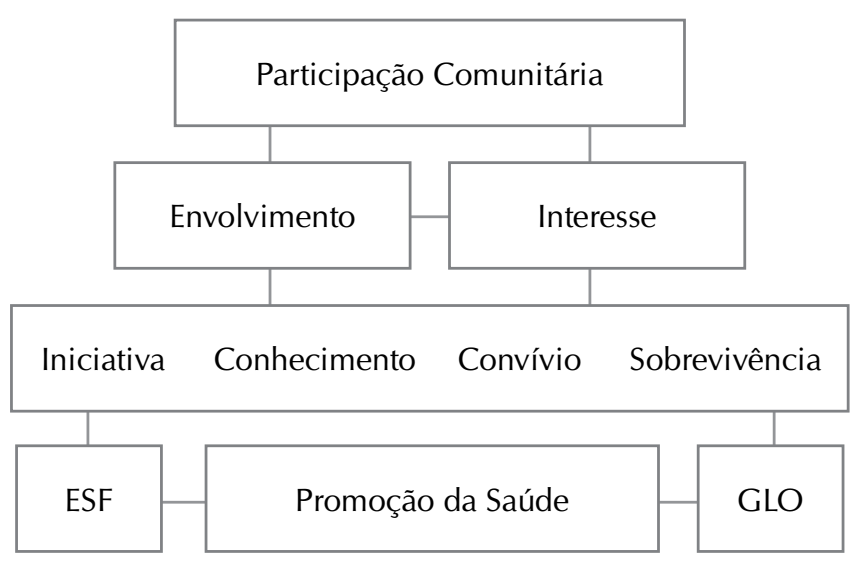

As categorias empíricas envolvimento e interesse dos grupos locais organizados emergem da narrativa dos envolvidos de modo não excludente. Elas articulam-se por apresentar subcategorias que se reafirmam na narrativa dos participantes, quais sejam: solicitação, conhecimento, convívio e sobrevivência.

Por se tratar de pesquisa com seres humanos atendeu-se a Resolução do Conselho Nacional de Saúde n 196/96, obtendo a aprovação do Comitê de Ética em Pesquisa da Universidade Federal do Rio Grande, parecer n. 52/2008 e, das secretárias municipais. Utilizou-se o Termo de Consentimento Livre e Esclarecido do Participante e códigos para identificação das entrevistas, quais sejam: $M$ (município), G (grupo), P (participante).

\section{RESULTADOS}

O conjunto de informações apresentadas evidencia a promoção da saúde desencadeada pela participação comunitária. A categoria envolvimento comunitário revela a mobilização dos profissionais da ESF e dos moradores como forma de gestão participativa da saúde. O interesse em participar dos grupos locais organizados indica as proposições individuais que se potencializam em coletivo e refletem-se no atendimento das necessidades humanas básicas psicobiológicas e socioambientais. 
O envolvimento comunitário nos grupos locais organizados

A participação das artesãs nos grupos foi referida por 19 $(54,28 \%)$ das 35 envolvidas como decorrente do convite da equipe da ESF, especialmente dos agentes comunitários de saúde, com 17 (48,57\%) referências. Exemplos:

(...) elas [agentes comunitários de saúde] vão à casa da gente e pedem pra gente vir (...) eu sei que é bom, a gente aprende alguma coisa, não fica pensando bobagens, sai de casa (...) (M01 G01 P03).

Fui convidada por uma Agente (M01 G03 P05).

Soma-se a essas, aquelas que referiram experiência prévia e afinidade com este tipo de trabalho manual, 14 (40\%) referências, tal como:

(...) sempre fiz esses trabalhos manuais (...) já até vendi e ganhei um dinheirinho, fui a festinhas e levei como presente (...) isso é bom porque a gente pode sair, sem ficar constrangida por não ter nada para levar de presente (M01 G02 P06).

Outras $14(40 \%)$ revelaram o desejo em aprender e ensinar; $13(37,14 \%)$ referiram ainda que o envolvimento deu-se como uma forma de valorização dos seus conhecimentos e das suas habilidades pela equipe da ESF.

Venho para cá para me distrair e fazer alguma coisa, a gente tem que fazer alguma coisa assim para aprender (M01 G05 P18).

Porque eu queria aprender, no caso, talvez amanhã ou depois, ter um ganho com isso. (M01 G02 P32).

Porque eu tenho a oportunidade de ensinar, conhecer mais gente e mais gente aprender a fazer o que eu sei fazer (M01 G01 P01).

A gente aprende a conviver com as pessoas, a ter mais conhecimento, participar, como se diz, da comunidade (M01 G04 P22).

Essa valorização e reflete ainda no âmbito familiar, pela composição da renda, para 07 (20\%) envolvidas.

Em primeiro lugar porque eu acho que o artesanato ajuda muito na renda familiar e porque eu amo artesanato, é uma das paixões que eu tenho, e acho que muitas pessoas através do artesanato sobrevivem (M01 G03 P27).

Para $06(17,14 \%)$ o envolvimento representou uma possibilidade de compartilhar seus anseios com pessoas que vivenciam uma mesma realidade social e de construir suporte para o enfrentamento das problemáticas decorrentes desta.

Por causa das amizades, eu gostei, são boas, a gente brinca bastante, conversa bastante, troca um monte de ideia (M01 G02 P26).
Eu me senti bem, sabe, é só pra mulher e a gente conversa e aí uma desabafa, outra troca receita e inventa de fazer um bolo, sabe, então eu me senti bem, então continuei participando (M01 G05 P16).

Dos 08 envolvidos nos grupos de conselheiros locais de saúde, 06 (75\%) referiram a solicitação da equipe da ESF como motivação para sua participação,

[...] foi quando eu comecei a participar de saúde mental, (...) me convidaram para participar, para apóia o trabalho do posto médico pra gente mexe com as coisas (M01 G07 P03).

Outros $06(75 \%)$ referiram o próprio interesse pelo trabaIho dos profissionais; $05(62,5 \%)$ buscam contribuir para o atendimento das necessidades da comunidade, por exemplo,

Foi por problema de saúde que eu vi certas ineficiências, certas carências mesmo do atendimento, fiquei sabendo da reunião, pedi mais detalhe, eles falaram detalhes pra mim, disseram que seria interessante e eu como não sou de fugir (...) (M01 G06 P02).

Outro refere a experiência em outros grupos comunitários organizados como fator de estímulo à sua participação,

(...) fui escolhida pela Pastoral DST/AIDS para ser uma das delegadas e quando nós chegamos nessa pré-conferência à gente viu assim que o município tinha propostas boas, tinha coisas boas, mas para o município. E que a nossa realidade local era outra bem diferente, que nós tínhamos outras necessidades básicas que não era bem aquilo ali, então a gente precisava montar um grupo. Aí então foi quando a gente foi informado de que nós podíamos montar um Conselho Local de Saúde e a gente começou a se reunir (M01 G07 P05).

No grupo de recicladores de resíduos sólidos a participação de 05 (100\%) deu-se como uma oportunidade de obtenção de renda para a totalidade dos envolvidos,.

As gurias me convidavam, eu não queria, eu não vou nada, mas aí depois eu disse, na verdade eu to precisando de dinheiro (...) (M01 G08 P04).

Porque as gurias me convidaram para fazer o curso e eu fui ficando, ficando e fiquei (M01 G08 P02).

Porque eu gosto, para mim foi uma boa porque eu tinha problema de nervos e aqui, melhorei um monte, melhorei mesmo (...) (M01 G08 P03).

A necessidade econômica do coletivo de pescadores, 05 $(100 \%)$ foi referida como motivação para o envolvimento dos mesmos.

Eu estava desempregado, parado, pescando, aí os guris me convidaram, faltava um alguém para transportar o peixe 
até a fábrica ou pegar um gelo (...) a gente precisa de dinheiro para ter saúde, pra comer, comprar até os remédios (M01 G09 P02).

Agrega-se ainda o conhecimento referido por 02 (40\%) dos envolvidos a respeito dos incentivos governamentais para o desenvolvimento organizado do trabalho deste setor produtivo da sociedade, tal como:

Nós temos um programa, fazemos parte do RS Pesca que através da nossa participação a gente consegue arrumar as embarcações, as redes, até comprar alguma coisinha para a sede como os frízeres (...) em parceria com o pessoal conseguimos material de construção e nós [os pescadores] decidimos quem são os pescadores que precisam ou outras pessoas da comunidade de casa e nós construímos (...) assim a gente ajuda muito na saúde da comunidade (M01 G09 P04).

A construção do Grupo de Moradores consolida-se a partir da existência de um trabalho voluntário prévio para 17 $(100 \%)$ dos envolvidos que permitiu a agregação de novos integrantes por meio do convite realizado a $08(47,05 \%)$ dos envolvidos.

Eu já fazia parte (...) nós arrecadamos roupas, alimentos e distribuímos nas comunidades há muito tempo (...) há pouco fui convidada para fazer parte de um grupo daqui, dessa comunidade (M02 G10 P05).

Outro interesse referido por $02(11,76 \%)$ envolvidos constitui-se na manutenção do trabalho da ESF e para 01 (5,88\%) na possibilidade de trocar experiências e aprender com o outro.

(...) o estatuto diz que tem que ter eleições de dois em dois anos, é uma coisa assim, que tu não ganha nada (...). Então as pessoas não estão muito dispostas a se doarem. E a gente tem uma ideia que ela [grupo comunitário local] não pode se extinguir por causa do PSF, que se extingue, compromete o PSF, então por isso, por estes motivos assim que a gente sempre tem mantido (...) de dois em dois anos tem eleição (M02 G10 P01).

(...) a gente aprende conversando um com o outro, contando dos problemas, como fez para resolver, indica quem pode ajudar, onde deve ir porque, às vezes, as pessoas nem se dão de conta que aquela pessoainha já passou por isso ou algo parecido, não é, e sabe como fazer (M02 G12 P09).

\section{$O$ interesse da comunidade em participar dos grupos lo- cais organizados}

Do conjunto das 35 artesãs, 24 (68,57\%) referem que o processo de ensino-aprendizagem constitui-se na principal finalidade do trabalho do coletivo, como:

(...) é muito porque as pessoas vêm pra cá, passam à tarde, uma aprende o que não sabe, às vezes, eu venho pra cá e ensino elas e eu aprendo o que eu não sei (M01 G01 P01).
A valorização da sua participação foi referida por 20 $(57,14 \%)$ envolvidas como fator para alcance do bem-estar/ saúde e por $16(45,71 \%)$ como a possibilidade de contribuir para a renda familiar, outras $11(31,42 \%)$ salientam a interação com outras mulheres da comunidade como fator propulsor à sua participação neste coletivo, conforme relato:

Aprenderem alguma coisa, até melhora a renda familiar, pra fazer algum trabalho, alguma coisa, e até mesmo pra pessoa não entra, não entra numa depressão (M01 G03 P05).

Dos 08 envolvidos nos Grupos de Conselheiros Locais de Saúde, $05(62,5 \%)$ revelam que o trabalho produzido decorre do interesse em dar resolutividade às ações em saúde realizadas pela equipe da ESF, por exemplo:

Acompanhar, fiscalizar, deixa vê, viabilizar, viabilizar soluções (...) do ponto de vista do Conselheiro (M01 G06 P02).

Outros 05 (62,5\%) expressam também a relação com a ESF ao referirem a busca, por meio de reivindicações, de melhorias na infraestrutura e nos recursos materiais,

É fazer a melhora do posto médico dentro deles, aqui, nas atividades (...) (M01 G07 P03).

E $01(12,5 \%)$ refere que o interesse está em fiscalizar as ações promovidas pela equipe da ESF, veja:

(...) como faltava medicamentos para a unidade, para a gente ter como pedir, como arrumar as ruas, limpar as valetas, pra começar a tirar os lixos dos bairros (...) entra nesse grupo por causa disso, pra reclama, e como reclama, e a gente reclama e pede, eles não atendem num dia e no outro dia a gente ta batendo lá de novo, não atende por telefone a gente vai pessoalmente (M01 G06 P07).

Os Grupos de Moradores investigados compuseram-se de 17 envolvidos, dos quais $16(94,11 \%)$ se referem à manutenção das condições sanitárias da comunidade para o alcance do bem estar/saúde e para a formação educacional dos moradores como interesse primordial do coletivo.

É o que sempre se fez os eventos, sempre o lucro visado nos eventos eram tudo em beneficio da comunidade, assim melhorias ambientais (M02 G10 P04).

(...) cada diretoria tem o seu objetivo, (...) muitos objetivos em comum a limpeza da praça, a coleta seletiva (M02 G10 P05).

Outros 05 (29,41\%) envolvidos destacam a orientação comunitária, o oferecimento de atividades de lazer e a doação de gêneros alimentícios como proposição do trabalho desenvolvido.

Propiciar momentos de lazer, (...) de alegria por mais que eles sejam poucos. Eu trabalho com crianças então, eu sei 
que um pouquinho de momentos de alegria, um pouquinho de momentos de lazer, pra essas crianças já é muito, pode parecer que não, mas fica marcado pra eles por muito tempo (M02 G11 P10).

A interação da comunidade com os gestores municipais para a negociação do alcance das necessidades locais foi referida por 04 (23,52\%) envolvidos.

(...) trabalhar em prol da comunidade, por que o presidente do bairro ele tem acesso ao poder público. É um porta-voz do bairro, das necessidades de melhoria do bairro (...) (M02 G10 P01).

O objetivo é trabalhar em prol da comunidade, com o objetivo de levar conhecimento a nossa comunidade, tentar fazer com que os moradores tenham uma escola dentro do bairro, que agora já temos o CAIC, uma quadra de esportes a qual conseguimos através de um projeto também e agora agente tem lutado pra conseguir um posto mesmo, um posto de saúde do bairro mesmo (M03 G11 P07).

Dois $(11,76 \%)$ identificam no trabalho da associação uma fonte alternativa para aquisição de uma renda, como:

(...) conseguir renda, um pouquinho mais de renda pra população, fazer sabão, pegar óleo velho, (...) ele também prejudica o meio ambiente (...) (M02 G10 P05).

O alcance de uma renda em troca do trabalho realizado pelo grupo de recicladores e a possibilidade de contribuir para a manutenção da limpeza do meio ambiente comunitário foram referidos por 03 (60\%) dos 05 envolvidos como principais objetivos para o desenvolvimento do trabalho do coletivo.

Ganhamos pouco, mais trabalhamos por isso, esse dinheiro e já ajudamos a limpar a comunidade não é os lugares ficam mais limpos até para as crianças brincarem (...) (M01 G08 P04).

Um (20\%) referiu os cuidados com o meio ambiente como uma forma de ajudar a comunidade na manutenção do bem-estar/saúde, de acordo com o relato:

Nós limpamos tudo, ajudamos a limpar o lixo das casas porque as pessoas jogam tudo na frente, agora já aprenderam mais, dependuram os sacos para os cachorros não rasgarem (...) tudo mais limpo fica melhor pra gente olhar, a gente se sente melhor em casa, caminhando na rua, pra receber visita porque às vezes o cheiro ruim vem do lixo que o vizinho deixou atirado (M01 G08 P03).

Para os pescadores o desenvolvimento do trabalho em coletivo representa, prioritariamente, a possibilidade para 04 $(80 \%)$ dos 05 envolvidos em torná-lo formal.

O objetivo do grupo é trabalhar na legalidade, é muito burocrático, mas e não se quer trabalhar fora dela também (M01 G09 P03).

E, $01(20 \%)$ refere à garantia do valor do produto no processo de negociação como interesse primeiro do coletivo.

A gente tem o objetivo que ele [pescador] pesque seu peixe e saiba quando ele está vendendo, quanto ele vai ganhar, vai dar valor ao seu produto, vai cuidar dele (M01 G09 P01).

\section{DISCUSSÃO}

A promoção da saúde como resultante da interação dos grupos locais organizados da comunidade com os profissionais da ESF revela a potencialidade, para além do trabalho da área da saúde, dos próprios moradores da comunidade em intervir em sua realidade.

Intervenção que ao emergir da iniciativa dos profissionais indica que tal trabalho em saúde os permite conhecer e transformar as vulnerabilidades dos moradores em motivação para o desenvolvimento e fortalecimento de potenciais individuais.

No âmbito deste trabalho, os enfermeiros caracterizam a comunidade pela compreensão dos aspectos que determinam a saúde local ${ }^{(1)}$. Eles desenvolvem suas ações pautadas no modo de viver e de sobreviver da comunidade assegurando, assim, uma interação que mantém a saúde pela participação comunitária no próprio modo de trabalho da equipe ${ }^{(8)}$.

O envolvimento e o interesse, neste sentido, estão implicados na aproximação entre profissional e comunidade, com fins de construir uma relação interpessoal de confiança. Esta se fortalece pela melhora clínica da problemática momentânea que acomete o cliente e, especialmente pela manutenção de uma interação que valoriza a participação comunitária no trabalho da equipe da ESF e nas ações de integração entre membros da própria comunidade.

O trabalho de acompanhamento e monitoramento da saúde dos moradores realizados pelos profissionais da ESF configura-se como um momento de encontro. Para os enfermeiros, neste instante, é possível promover à saúde, especialmente, porque se produz um diálogo bidirecional entre os envolvidos. Interação que gera a ampliação das estratégias de autocuidado e, mais do que um diálogo preventivo, desencadeia sentimentos de pertença e de identificação do morador com sua comunidade, mediado pelo trabalho em saúde ${ }^{(9)}$.

Paralelamente à iniciativa dos profissionais, o conhecimento como o desejo expresso pelos moradores em estimular suas habilidades e apreender novas práticas por meio das ações desenvolvidas nos grupos locais organizados representa que o potencial individual se fortalece em coletivos e pelo trabalho da equipe de ESF.

Fortalecimento marcado pela capacidade de estímulo ao pensar produtivo, que ocupa o tempo do cotidiano da vida comunitária e propicia mais do que aprender, desenvolver ou aperfeiçoar habilidades individuais. Contribui para o afastamento de problemas que tornam os moradores vulneráveis às adversidades socioambientais. 
No ambiente de trabalho da ESF, a negociação para a participação dos moradores nas ações de promoção da própria saúde demonstra que o enfermeiro favorece o acesso ao atendimento das necessidades clínicas ${ }^{(5)}$. Em contrapartida a participação comunitária nas ações conjuntas torna-se ativa pela liberdade em interagir solicitando esclarecimentos e escolhendo os assuntos de interesse particular que serão abordados garantindo a privacidade do desejo do morador ${ }^{(10)}$, fator que evita constrangimentos e delimita interesses comuns ${ }^{(11)}$.

O conhecimento evidenciado estabelece um caráter dinâmico às relações interpessoais. Se por um lado os moradores têm na equipe da ESF um meio para obter maior suporte à promoção de sua saúde, por outro revelam que este os permite arguir os profissionais da saúde em prol de seus interesses para torná-los comuns a ambos.

A comunalidade de interesse entre os envolvidos em uma interação constitui-se no alicerce para constituição e consolidação de um ambiente de trocas pela compreensão das relações estabelecidas ${ }^{(12)}$. Tal compreensão implica na forma de participação dos moradores nos grupos locais organizados e na relação destes com os profissionais da saúde.

$O$ trabalho da equipe da ESF ao mediar às relações interpessoais promove a gestão participativa das ações comunitárias que se consolida pelo interesse da comunidade em articular-se para mantê-lo e para qualificá-lo em termos de condições de trabalho. Para tanto, o conhecimento da sua funcionalidade propulsiona a participação comunitária que se sentem impelida a dar suporte às negociações entre profissionais e gestores.

Os gestores municipais buscam caminhos para atender a diversidade de necessidades dos moradores e das comunidades e entre tais, a interação como os clientes do trabalho da ESF, promove a resolutividade dos serviços. Contudo, se por um lado há liberdade no trabalho da ESF para promover a participação e o restabelecimento da saúde, por outro existe uma fiscalização do cumprimento das metas de produtividade. Assim, coexistem normatizações distintas entre os profissionais envolvidos neste tipo de produção em saúde ${ }^{(13)}$.

A participação da comunidade no trabalho da ESF por meio dos grupos locais organizados converge para afirmar a implementação de uma nova proposta de atenção à saúde. Proposta que almeja intervir em situações de risco para amenizar os efeitos deletérios do processo de desenvolvimento dos povos ${ }^{(14)}$.

O chamamento para participar dos grupos locais organizados pode também ocorrer por iniciativa dos próprios envolvidos, especialmente, pela identificação da necessidade de aquisição de uma fonte de renda ou ainda quando já há o desenvolvimento e conhecimento do modo de trabalho em coletivo. Os participantes envolvem outros moradores pela expressão de interesses comuns que perpassam a questão econômica individual e insere-se no âmbito das necessidades humanas básicas de recreação, gregária, lazer, entre outras de cunho coletivo.

O isolamento social, a impossibilidade de expressar-se ou de comunicar-se provoca o adoecimento psicobiológico nas comunidades $^{(15)}$. A essência da condição humana está implicada na necessidade de sentir-se integrante de um coletivo conceituado ou definido socialmente, mesmo que cada morador de uma comunidade tenha em si sua singularidade que se conforma na pluralidade e potencialidade do ser, fazer, querer coletivo ${ }^{(16)}$.

O envolvimento nesta interação compõe-se do interesse individual em suprir suas necessidades humanas básicas que na dinâmica das ações de trabalho transbordam a competitividade das relações formais para produzir suporte à comunidade pelo acesso a informações que promovem a saúde ${ }^{(17)}$.

O convívio decorrente deste modo de atender às necessidades individuais de uma comunidade foi ressaltado pelos moradores envolvidos nos grupos locais organizados como fator para o alcance do bem-estar. Este como resultado do incentivo dos profissionais da ESF ou dos próprios moradores à participação, cuja é capaz de valorizar o conhecimento, a experiência e as habilidades refletindo-se em mais do que uma forma para aproximar os moradores e identificar as estratégias locais de enfrentamento das vulnerabilidades. Valorização que se irradia para as interações sociais devido à possibilidade de produzir renda e contribuir para a sobrevivência familiar.

A promoção da saúde, nesta perspectiva, caracteriza-se pela solidificação do autocuidado como expressão do potencial de postar-se cotidianamente frente a situações de tomada de decisões que repercutirão sobre os desejos de apreender saberes, buscar verdades e produzir o bem-estar para si e para outrem ${ }^{(18)}$.

Desejos que obtêm nas ações do trabalho da equipe da ESF um meio para sua viabilidade, já que laços de amizade são construídos a partir de interações que propiciam lazer, entretenimento e diversão concomitantemente a manutenção da condição de saúde da comunidade, cuja articulação está assegurada nas e pelas ações do enfermeiro ${ }^{(5)}$.

O trabalho do enfermeiro na ESF provoca um mútuo e recíproco atendimento às necessidades humanas básicas da comunidade na interação desencadeada entre o profissional e representantes dos grupos locais organizados por permitir a concretização da gestão participativa em saúde ${ }^{(19)}$. Esse profissional fundamenta-se em um conhecimento clínico específico da enfermagem para intervir na complexidade dos determinantes locais da saúde avançando, assim, em termos de resolutividade das problemáticas comunitárias ${ }^{(20)}$.

Seu trabalho apoia-se nos desejos da comunidade para promover a saúde na simplicidade da (re)significação da autoimagem dos participantes dos grupos locais organizados. Avançando amplamente para consolidação da própria ESF, bem como para a qualidade das relações interpessoais e de saúde dos moradores.

A investigação da participação comunitária apresentada tem como limite a valorização da organização dos moradores no envolvimento e na definição de interesses em conjunto com o trabalho da equipe de ESF em detrimento a especificidade do tipo de produção realizada nos grupos locais organizados por entender que a promoção da saúde está para além da aquisição de renda, mas na autovalorização dos envolvidos como forma de estimular o bem-estar dos e para os moradores. 


\section{CONCLUSÃO}

A participação comunitária investigada decorre da interação entre moradores e destes com a equipe da ESF com a finalidade de promover a saúde dos indivíduos e do ambiente natural comunitário. Assim, o envolvimento e o interesse da comunidade em participar dos grupos locais organizados decorrem da iniciativa dos profissionais da saúde e dos moradores, já participantes desses grupos, para disseminar informações e conhecimentos a respeito do acesso e do modo de trabalho do serviço local de saúde, ou seja, da ESF.

A participação contribui para o convívio de moradores que buscam alternativas para a manutenção e estabelecimento de um maior grau de saúde, promovido nos grupos pela interação interpessoal. Esta corrobora para a sobrevivência dos envolvidos pela melhoria do bem-estar individual que fortalece a participação produtiva. Logo, o trabalho tem como resultado a produção da capacidade de negociação de mercadorias comercializáveis, de modo que, ele implica na aquisição de melhorias socioambientais e de renda.

Deste modo, a promoção da saúde se expressa nas ações dos grupos locais organizados que buscam a saúde para si, intervindo no seu modo de viver e de sobreviver, ou seja, agindo sobre os danos da ação humana. Paralelamente, os participantes se fortalecem porque conquistam maiores possibilidades de serem (re)conhecidos como sujeitos capazes de provocar mudanças no contexto local, na e para a saúde e a natureza.

A contribuição deste estudo está para além do estímulo às ações de gestão participativa no âmbito da saúde, mas em destacar o potencial existente nas comunidades, fundamento a ser explorado pela ampliação do convívio dos interessados em promover à saúde e garantir a sobrevivência das comunidades.

\section{REFERÊNCIAS}

1. Ministério da Saúde. Secretária de Atenção à Saúde. Departamento de Atenção Básica. Política Nacional de Atenção Básica. 4. ed. Brasília, DF: Ministério da Saúde; 2007.

2. Cezar-Vaz MR, Weis AH, Costa VZ, Soares JFS, Bonow CA, Cardoso LS, et. al. Estudo com enfermeiros e médico da atenção básica à saúde: uma abordagem socioambiental. Texto \& Contexto Enferm. 2007;16(4):645-53.

3. Ministério da Saúde. Promoção da saúde: carta de Otawa, Declaração de Adelaide, Declaração de Sunsvall, Declaração de Jacarta, Declaração de Bogotá. Brasília, DF: Ministério da Saúde; 2001.

4. Scliar M. PHYSIS: História do conceito de saúde. Rev Saúde Coletiva 2007;17(1):29-41.

5. Ministério da Saúde. Secretária de Vigilância em Saúde. Política Nacional de Promoção da Saúde. Brasília, DF: Ministério da Saúde; 2006.

6. Lopes MSV, Saraiva KRO, Fernandes AFC, Ximenes LB. Análise do conceito de promoção da saúde. Texto \& Contexto Enferm. 2010;19(3):461-8.

7. Silverman D. Interpretação de dados qualitativos: métodos para análise de entrevistas, textos e interações. Porto Alegre: Artmed; 2009.

8. Sant'Anna CF, Cezar-Vaz MR, Cardoso LS, Erdmann AL. Determinantes sociais de saúde: características da comunidade e trabalho das enfermeiras na saúde da família. Rev Gaúcha Enferm. 2010; 31(1):92-9.

9. Cardoso LS, Cezar-Vaz MR, Silva MR, Costa VZ. The purpose of the communication process of group activities in the family health strategy. Rev Latino-Am Enferm. 2011;19(2):396-402.

10. Cardoso LS, Cezar-Vaz MR, Bonow CA, Sant'Anna CF. Communication process: a group activities tool in the family health strategy. Rev Esc Enferm USP. 2011;45(6):1323-30.
11. Rocha LP, Cezar-Vaz MR, Cardoso LS, Almeida MCV. Processos grupais na estratégia saúde da família: um estudo a partir da percepção das enfermeiras. Rev Enferm UERJ. 2010;18(2):210-5.

12. Silva LAA, Mercês NNA, Schmidt SMS, Marcelino SR, Pires DEP, Carraro TEL. Um olhar sócio-epidemiológico sobre o viver na sociedade atual e suas implicações para a saúde humana. Texto \& Contexto Enferm. 2006;15(esp.):170-7.

13. Martino LMS. Teoria da Comunicação: ideias, conceitos e métodos. Petrópolis: Vozes; 2009.

14. Figueiredo PP, Cezar-Vaz MR, Soares JFS, Sena J, Cardoso LS. Processo de trabalho da estratégia saúde da família: a concepção de gestão que permeia o agir em saúde. Physis. 2010;20(1):235-59.

15. Horta WA. Processo de enfermagem. São Paulo: Editora EPU-EDUSP; 1980.

16. Arendt H. A condição humana. 11. Ed. Rio de Janeiro: Forense Universitária; 2010.

17. Otero Martínez H. Hacia una comunicación efectiva y humanista en ámbitos de salud. Rev Habanera Cienc Méd. 2008;7(1):1-10.

18. Bub MBC, Medrano C, Silva CD, Wink S, Liss PE, Santos EKA. A noção de cuidado de si mesmo e o conceito de autocuidado na enfermagem. Texto \& Contexto Enferm. 2006;15(esp.):152-7.

19. Sant'Anna CF, Cezar-Vaz MR, Cardoso LS, Bonow CA, Silva MR. Comunidade: objeto coletivo do trabalho das enfermeiras da estratégia saúde da família. Acta Paul Enferm. 2011;24(3):341-7.

20. Cezar-Vaz MR, Cardoso LS, Bonow CA, Sant'Anna CF, Sena J. Conhecimento clínico do enfermeiro na atenção primário à saúde: aplicação de uma matriz filosófica de análise. Texto \& Contexto Enferm. 2010;19(1):17-24. 